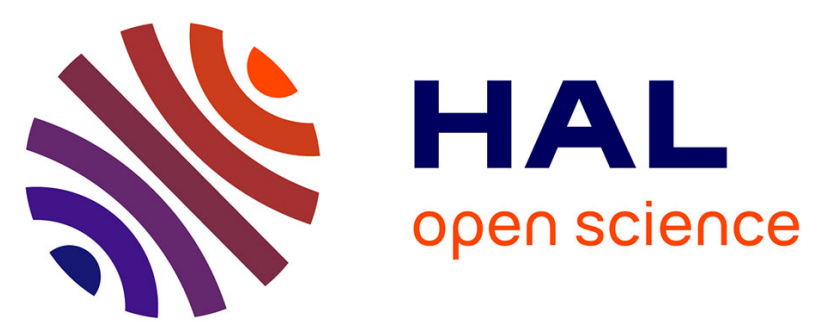

\title{
Energy Consumption Estimation in Different Climates of a Solar Combisystem Combined with an Absorption Chiller
}

A. Lazrak, Gilles Fraisse, Antoine Leconte, Bernard Souyri, Philippe Papillon

\section{To cite this version:}

A. Lazrak, Gilles Fraisse, Antoine Leconte, Bernard Souyri, Philippe Papillon. Energy Consumption Estimation in Different Climates of a Solar Combisystem Combined with an Absorption Chiller. ISES Solar World Congress 2015, Nov 2015, Daegu, South Korea. pp.1-10, 10.18086/swc.2015.10.32 . cea02948522

HAL Id: cea-02948522

https://hal-cea.archives-ouvertes.fr/cea-02948522

Submitted on 25 Sep 2020

HAL is a multi-disciplinary open access archive for the deposit and dissemination of scientific research documents, whether they are published or not. The documents may come from teaching and research institutions in France or abroad, or from public or private research centers.
L'archive ouverte pluridisciplinaire HAL, est destinée au dépôt et à la diffusion de documents scientifiques de niveau recherche, publiés ou non, émanant des établissements d'enseignement et de recherche français ou étrangers, des laboratoires publics ou privés. 


\title{
Energy Consumption Estimation in Different Climates of a Solar Combisystem Combined with an Absorption Chiller
}

\author{
Amine Lazrak ${ }^{1,2,3}$, Gilles Fraisse ${ }^{2}$, Antoine Leconte ${ }^{1}$, Bernard Souyri ${ }^{2}$ and Philippe Papillon ${ }^{1}$ \\ 1 INES/CEA, Le Bourget-du-Lac (France) \\ 2 LOCIE/CNRS, Le Bourget-du-Lac (France) \\ ${ }^{3}$ ADEME, Angers (France)
}

\begin{abstract}
Currently there is no global approach to model then characterize solar thermal systems for building application. Results of the existing approaches are valid only for specific conditions (climate and thermal building properties). In a previous study a generic methodology to model solar combisystems (SCS) was developed. This methodology was applied to predict the energy consumption of two kinds of systems: SCS combined with a gas boiler and SCS combined with a heat pump. In the current paper, an extension of the methodology to SCS combined with an absorption chiller is presented. The methodology is based on the development of an artificial neural network (ANN) that models the dynamic of the system. The developed neural models were able to predict, with a good precision degree, the annual energy performance of the system in different climates based on a learning sequence of only 12 days. The satisfactory results emphasize the generic character of the methodology and show that it could be used, in the future, as an energy performance evaluation tool. Also, the proposed approach will be helpful in the context of energy performance guarantees.
\end{abstract}

Keywords: Thermal systems, Absorption chiller, Performance estimation, Dynamic modelling, Artificial neural networks, System testing.

\begin{tabular}{|lll|}
\hline Nomenclature & & \\
$P_{d h w}$ & Heat flow rate supplied for the Domestic Hot Water (DHW) & $(\mathrm{kW})$ \\
$A$ & Solar collector area & $\left(\mathrm{m}^{2}\right)$ \\
$G$ & Global irradiance & $\left(\mathrm{kW} . \mathrm{m}^{-2}\right)$ \\
$P_{s h}$ & Heat flow rate supplied for space heating & $(\mathrm{kW})$ \\
$P_{a u x}$ & Power of the auxiliary system (electric back up system) & $(\mathrm{kW})$ \\
$P_{s c}$ & Cooling power & $(\mathrm{kW})$ \\
$\mathrm{TD}$ & Time delay & \\
$\mathrm{AF}$ & Activation function & \\
$F^{\prime}$ & Collector efficiency factor & \\
$(\tau \alpha)_{e n}$ & Effective transmittance-absorptance product for direct solar radiation & \\
$K_{\theta d}$ & at normal incidence & $\left(\mathrm{W} / \mathrm{m}^{2} \mathrm{~K}\right)$ \\
$c_{1}$ & Incidence angle modifier for diffuse radiation & $\left(\mathrm{W} / \mathrm{m}^{2} \mathrm{~K}^{2}\right)$ \\
$c_{2}$ & Linear heat loss coefficient & $\left({ }^{\circ}\right)$ \\
$\beta$ & Non-linear heat loss coefficient & \\
$b_{0}$ & Collector inclination & \\
\hline
\end{tabular}

\section{Introduction}

Solar thermal systems combined with an auxiliary system such as a boiler, a heat pump or incorporating an absorption chiller, can play an important role in reducing energy consumption of buildings for space heating, cooling and domestic hot water production. In this sense, characterizing the energy performance of solar thermal systems is a crucial issue. 
Currently, the available methods are either based on several separate physical tests of the components of the system to be evaluated, which does not take into account the real interactions between them, or on physical models that can be complex and difficult to identify especially because today's systems are compact and prefabricated in the factory (Haller, et al., 2013), (Lazrak, Leconte, Chèze, Fraisse, Papillon, \& Souyri, 2015), (Leconte, Achard, \& Papillon, 2012). In the absence of a reliable method to estimate the solar thermal systems performance before their integration in the building, their market underwent major difficulties for its development (Eur'Observ'ER, 2013).

In this context it is essential to develop a generic methodology that can be applied to different types of systems which overcomes the difficulties encountered by current methods.

For this reason a generic methodology to model solar combisystems (SCS) was developed previously (Lazrak, Leconte, Chèze, Fraisse, Papillon, \& Souyri, 2015), (Lazrak, et al., 2015). This methodology was applied to predict the energy consumption of two kinds of systems: SCS combined with a gas boiler and SCS combined with a heat pump.

In this paper is presented an extension of the developed methodology to SCS combined with an absorption chiller. This new methodology can be used then to characterize any system based only on a short cycle test in a semi-virtual test bench. Also, by means of this technique it will be possible to evaluate the system energy consumption that it will have when installed in the environment that it was chosen for.

\section{Methodology}

\subsection{Overview of the proposed methodology}

A more detailed description of the methodology developed could be found in (Lazrak, Leconte, Chèze, Fraisse, Papillon, \& Souyri, 2015). It has been shown that the methodology developed is:

- Nonintrusive because there is no need to dismantle the system, to be tested, in order to apply the methodology.

- The method takes into account the whole system so all interactions between subsystems are modelled.

- $\quad$ The system procedure test is short.

- The method allows predicting the system performance for different climates.

These characteristics make the methodology relevant to overcome the weaknesses of the current methods. To show that it could be applied to several kinds of solar systems and thus investigate its generic character this method was applied to solar system combined with an absorption chiller.

The five steps to model and then to evaluate the performance of a system following the proposed approach are represented in Fig.1. Evaluating a system following the methodology developed consists on first testing the system to be characterized in a semi-virtual test bench during a short sequence of time, typically 12 days, and in a dynamic way. This short test is based on the SCSPT method developed at INES, the French solar national institute. Then, data harvested, serve to design a dynamic neural network model of the system (described in section 2.2.). Basically, the ANN learns the internal behavior of the tested system. The goal is to have a global model with good generalization ability such that it can evaluate the system energy consumption, over a year, even with unseen data. The model can then be used to estimate the system's annual performances for different conditions. As a consequence it is not required that the model reproduces faithfully the system behavior in an hourly or daily basis as long as it can estimate well enough the annual performance. The ANN developed is inherent to the system tested and thus cannot be used to replace other different system. 


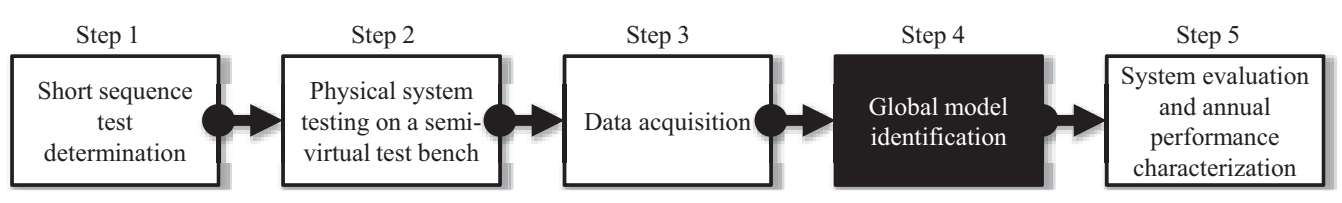

Fig. 1: Process stages of the proposed system's performance evaluation methodology

\subsection{Black box modelling using ANN}

Using Neural Networks seems to be the most powerful mathematic tool to solve this modelling problem. In fact, it was shown that neural networks are universal function approximators (Cybenko, 1989), so they can be used to approximate the system function. ANN were applied successfully to solve complex, non-linear, dynamic and multivariable problems. They tolerate errors, imprecisions and missing data as well (Kalogirou, 2001). Artificial neural networks were extensively used during the last decade.

The theory of ANN is clearly presented in (Dreyfus, 2005) and (Norgaard, Ravn, Poulsen, \& Hansen, 2000). ANNs are parametric analytical functions whose concept takes inspiration from the human central nervous system. A neuron, the basic element of an ANN, can compute values $z_{l}$ from a weighted summation of its inputs $x_{j}$. The summation coefficients $\omega_{j}^{l}$ are called synaptic weights. The subscript $l$ denotes the neuron number. The neural operation is presented in (eq. 1). The function $f_{l}$ is called the neural activation function (AF).

$$
z_{l}=f_{l}\left(\sum_{j=1}^{K} \omega_{j}^{l} x_{j}\right)
$$

Inter-connected neurons constitute what is commonly called a neural network. There are several network architectures and each one is more suitable for a specific problem than others. The most common architecture for prediction and fitting problems is the class of multi-layer perceptron (MLP). An MLP is a feed-forward network built of neurons, arranged in layers. It has an input layer, one or more hidden layers and an output layer. In (fig. 2) a MLP, with $E$ inputs, $C$ neurons in the hidden layer and $S$ outputs, is presented. The $s^{\text {th }}$ output of the network can be obtained using (eq. 2).

$$
y_{s}=f_{s}^{S}\left(\sum_{c=1}^{C} \omega_{c, s}^{S} f_{c}^{C}\left(\sum_{e=1}^{E} \omega_{e, c}^{C} u_{e}\right)\right)
$$
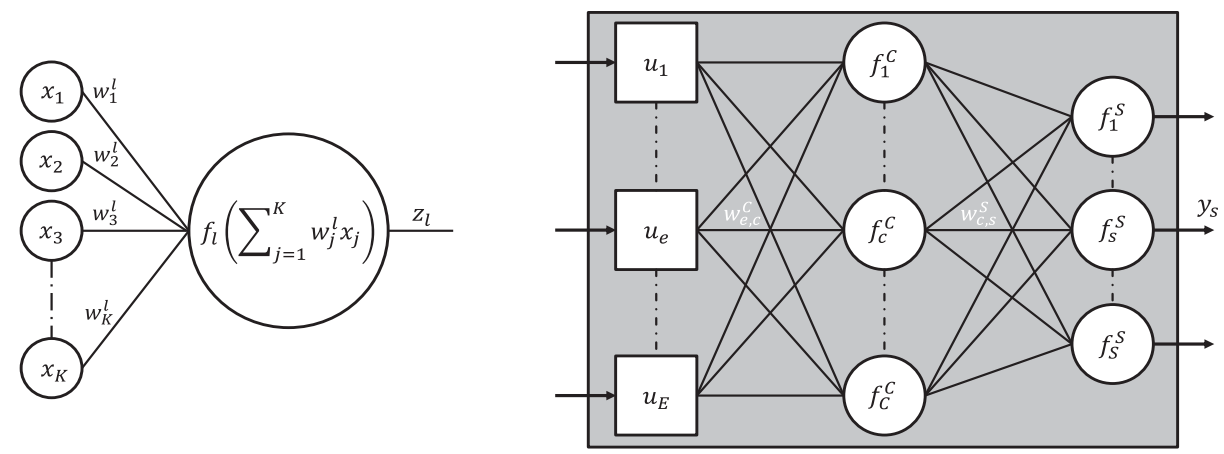

Fig. 2: Neuron formal representation (left), example of a neural network MLP with one hidden layer representation (right)

Neural network learning or training is the process of determination of an ensemble of weights so that the underlying function approximates the real system function. In fact, the objective of the training process is to minimize a cost function, with respect to weights, knowing a set of data. The short time of the system test, which is of 12 days, restricts the amount of available data for training. Therefore it is necessary to use a learning algorithm that can use a restricted data set without compromising the generalization ability of the model. For this reason it is relevant to use regularization method for the learning process. Typically, training aims to reduce the sum of squared errors see (eq. 3) with $t_{i}$ the target data at the sequence time $i$ and $y_{i}$ the $\mathrm{NN}$ output at the same time. Regularization modifies the objective function by adding an additional term: the sum of squares of the network weights (eq. 4), $q$ is the number of the neural network weights. By constraining the size of weights the training process produce an ANN with good generalization ability (MacKay, 1992). In fact, by keeping the weights small the ANN response will be smooth and so the over- 
fitting is supposed to be prevented. In this study the objective function optimization is done using the Levenberg-Marquardt algorithm.

$$
\begin{aligned}
& \text { sse }=\sum_{i=1}^{N}\left(t_{i}-y_{i}\right)^{2} \\
& \text { ssw }=\sum_{i=1}^{q} \omega_{i}^{2}
\end{aligned}
$$

Determination of the modelling input-output configuration is crucial to develop a generic methodology. Generally, solar thermal systems physical inputs and outputs differ from one to another. They depend on the energy sources used by the system and how this latter was designed by the manufacturer. However, energy systems can be represented in terms of power transformation between the renewable energy source, the loads and auxiliary system. This is why a compact configuration with four inputs: $P_{d h w}, A . G, P_{s h}, P_{s c}$ and one output $P_{\text {aux }}$ was selected. This open configuration, not particular to a specific system is relevant to develop a global and generic methodology. In (Lazrak, Leconte, Fraisse, Papillon, \& Souyri, 2014) results concerning a solar combisystem modeling show that a dynamic ANN model (NARX model) is more efficient than a static one. The latter does not learn the dynamic of the solar system especially due to the heat storage component, for this reason dynamic neural network (fig. 3) was used.

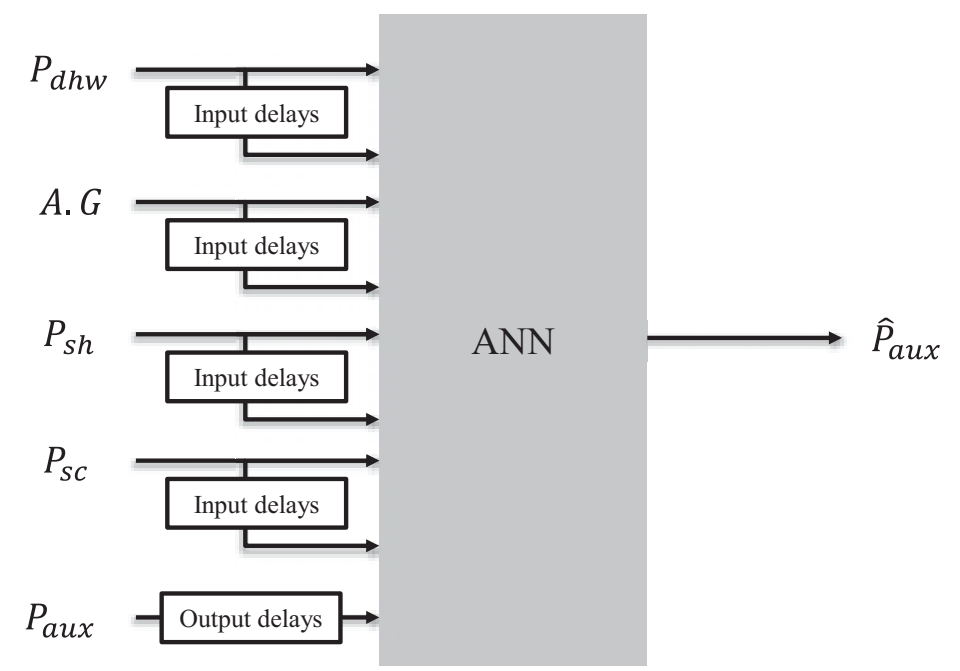

Fig. 3: NARX modelling configuration (open loop architecture), the hat "^" symbol indicates that the variable is predicted and not actual

Usually, regularization does not necessary guarantee the production of efficient networks. This is why it is essential to make some data preprocessing before training. By normalizing the input and target data vectors, the neural network training will be easier, faster and all vectors will be equally taken into account during the learning process. Equation (eq. 5) will be used to pretreat the training data in order to fall between $a$ and $b, x$ represent a vector of raw data through time.

$$
\text { Normalized variable }=\frac{\mathrm{x}-x_{\min }}{x_{\max }-x_{\min }}(b-a)+a
$$

The modelling time step is equal to $30 \mathrm{~min}$. It was noted that the on-off cycles of the auxiliary system generate discontinuities in data. To smooth the collected data, a moving average of five time steps was applied to them.

\subsection{Model Selection}

During the training process, several networks are created with different number of neurons in the hidden layer, re-initializations (in order to ovoid local minima), output AF (tanh and linear functions), time delays (TD) and normalization intervals. The Bayesian information criterion (BIC) was chosen to select the most relevant network (Dreyfus, 2005), (Qia \& Zhangb, 2001). It is defined by the following: 


$$
B I C=\ln M S E+q \frac{\ln N}{N} \quad \text { (eq. 6) }
$$

where $q$ is the number of model weights and $N$ the size of the learning data (number of samples).

The mean squared errors MSE (eq. 6) in BIC is calculated using the training data and in a closed loop architecture (Fig. 4) in which inputs and the initial values of the outputs, are used to predict the outputs (long-term model simulation) at future time steps.

Because the true output is available while the network is being trained, it is efficient to use it instead of feeding back the estimated output. The resulting architecture is called open loop architecture (Figs. 3 and 4). The advantage of this architecture (used only during training) is that the input to the ANN is more accurate.

The BIC selects ANNs (that have a lower BIC value) with a small number of parameters (synaptic weights). This is advantageous because ANNs with few parameters have a better generalization power, as stated in (Khosravi, Nahavandi, Creighton, \& Saeid, 2013).

The whole training and selection process was developed in MATLAB R2012b.
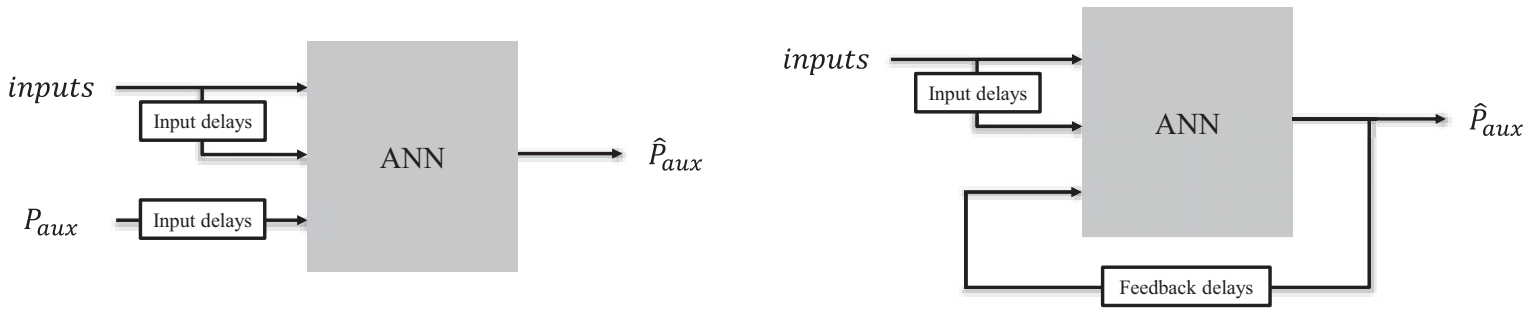

Fig. 4: Open loop architecture (left) and closed loop architecture (right)

In the following, the results of two different models for each system are presented:

- ANN1 is the model that is selected as the best model after the comparison of its performance with all the ANN models created in different boundary conditions (climate, building type).

- ANN2 is the model that would be selected based only on the BIC criterion.

\subsection{The solar system evaluated}

The system considered is an SCS combined with an absorption chiller. This system has been developed and designed within a national project. The goal of the project was to develop a system architecture that meets the following specifications:

- System intended for certain types of buildings of the Maghreb countries, southern Europe and the United States (Tab. 1).

- Systems with a limited number of hydraulic components (valves, circulation pumps and heat exchangers) to limit the risk of failure.

- Reduced cost

- System with good performance

The system is represented in (Fig. 5). It allows both solar discharge through the cooling tower and direct solar heating (without passing through the absorption chiller), if necessary with an electric online backup. This architecture uses only three-way valves to switch between different operating modes. This architecture uses specific units to prevent the risk of frost.

The physical characteristics of the system used to develop its TRNSYS model are given in (Tab. 2). 


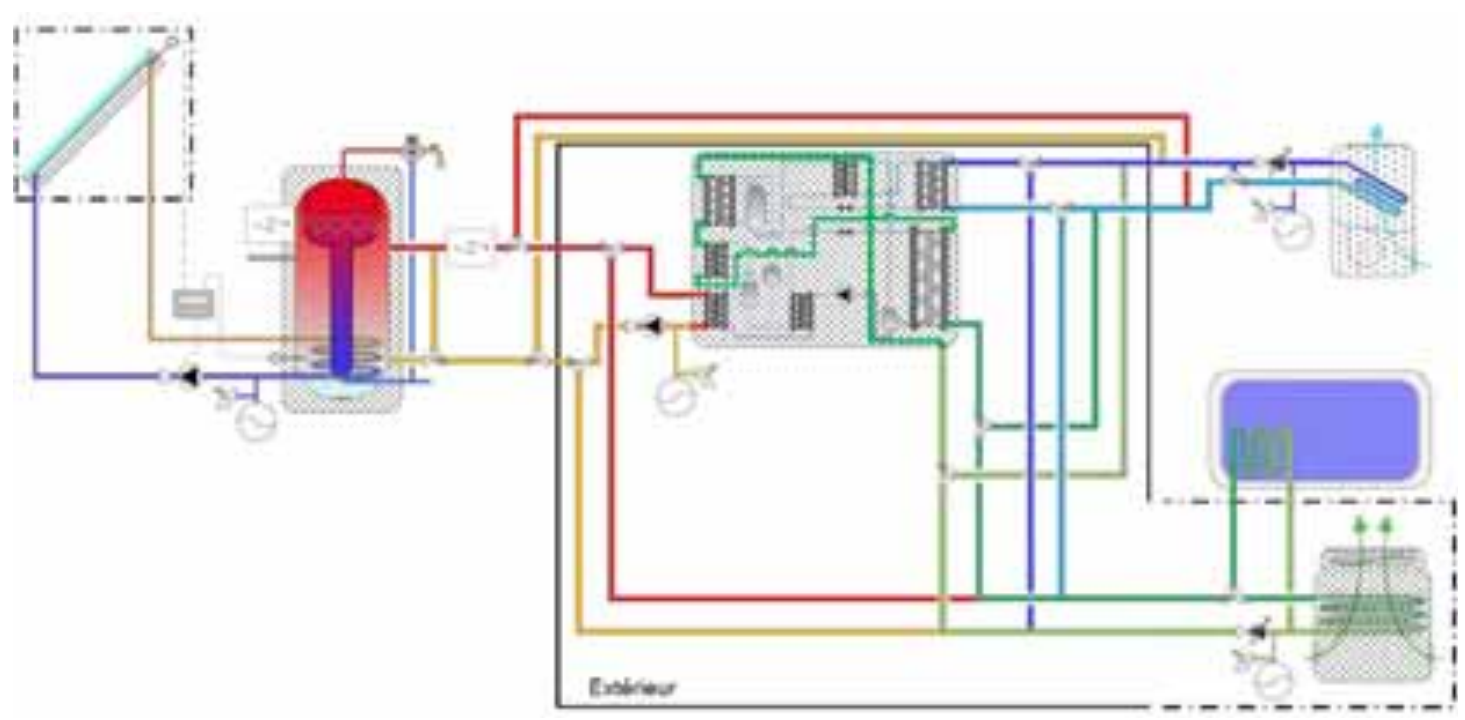

Fig. 5: Solar system combined with an absorption chiller hydraulic scheme

Training data are represented in (Fig. 6). They are the result of the system model simulation, using the AixEn-Provence climate and a representative building of Maghreb countries, according to the SCSPT method (only 12 days).

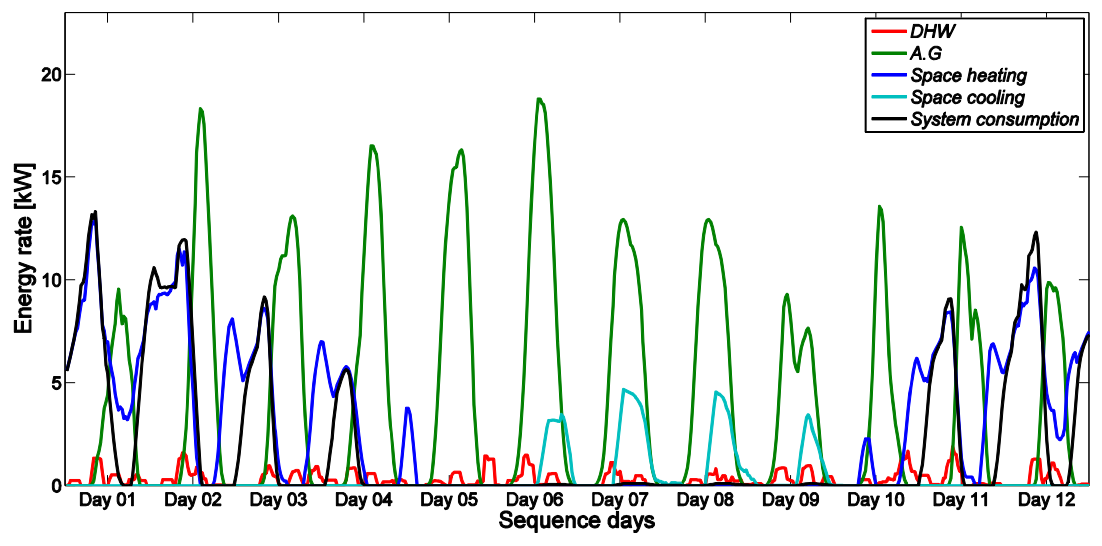

Fig. 6: Training data (SCSPT simulation results)

Tab. 1: Some characteristics of the buildings used as the boundary condition for each region

\begin{tabular}{|c|c|c|c|}
\hline Region & Europe & USA & Maghreb countries \\
\hline Area & $140 \mathrm{~m}^{2}$ & $300 \mathrm{~m}^{2}$ & $300 \mathrm{~m}^{2}$ \\
\hline $\begin{array}{c}\text { Reference energy } \\
\text { consumption }\end{array}$ & $\begin{array}{c}130 \mathrm{kWh} / \mathrm{m}^{2} \text { per year } \\
\text { in Rennes }\end{array}$ & $\begin{array}{c}130 \mathrm{kWh} / \mathrm{m}^{2} \text { per year in } \\
\text { Washington }\end{array}$ & $\begin{array}{c}60.7 \mathrm{kWh} / \mathrm{m}^{2} \text { per year in } \\
\text { Marrakech }\end{array}$ \\
\hline Materials of construction & Brick & Wood frame & Brick \\
\hline
\end{tabular}


Tab. 2: Physical characteristics of the system used in its TRNSYS model

\begin{tabular}{|c|c|c|}
\hline Remarks & TRNSYS Type & Parameter values \\
\hline \multicolumn{3}{|c|}{ Absorption chiller } \\
\hline $\begin{array}{c}\text { This type is not a standard one. It } \\
\text { was developed based on Ziegler } \\
\text { works (Ziegler, Hellmann, \& } \\
\text { Schweigler, 1999) }\end{array}$ & Type 881 & $\begin{array}{l}\mathrm{NH}_{3} / \mathrm{H}_{2} \mathrm{O} \text { absorption chiller } \\
\text { Nominal power: } 7 \mathrm{~kW} \text {. }\end{array}$ \\
\hline \multicolumn{3}{|c|}{ Electric auxiliary } \\
\hline Inside the storage tank & Equation bloc & Nominal power: $9 \mathrm{~kW}$ \\
\hline Electric online backup & Equation bloc & Nominal power: $24 \mathrm{~kW}$. \\
\hline \multicolumn{3}{|c|}{ Dry cooler } \\
\hline Heat exchanger + ventilator & Type 112 and Type 91 & $\begin{array}{l}\text { Nominal flow rate: } 6000 \mathrm{~kg} / \mathrm{h} \text {, } \\
\text { Ventilator consumption: } 190 \mathrm{~W}\end{array}$ \\
\hline \multicolumn{3}{|c|}{ Storage } \\
\hline $\begin{array}{l}\text { The heat exchanger for DHW } \\
\text { preparation is inside the storage } \\
\text { tank }\end{array}$ & Type 340 & $\begin{array}{c}10001 \text { of volume } \\
2 \mathrm{~m} \text { height } \\
10 \mathrm{~cm} \text { of insulation } \\
\text { Coefficient of lateral losses } 6.76 \mathrm{~W} \\
/ \mathrm{K} \text { and for the upper and lower } \\
\text { portions a value of } 0.62 \mathrm{~W} / \mathrm{K}\end{array}$ \\
\hline \multicolumn{3}{|c|}{ Solar collector } \\
\hline Developed by (Haller, 2012) & Type 832 & $\begin{array}{c}F^{\prime}(\tau \alpha)_{e n}=0.793 \\
K_{\theta d}=0.9 \\
c_{1}=0,749\left(\mathrm{~W} / \mathrm{m}^{2} \mathrm{~K}\right) \\
c_{2}=0,005\left(\mathrm{~W} / \mathrm{m}^{2} \mathrm{~K}^{2}\right) \\
\beta=45^{\circ} \\
b_{0}=0.18 \\
\text { Collector area }=23 \mathrm{~m}^{2}\end{array}$ \\
\hline
\end{tabular}

\section{Results and discussion}

Several annual simulations were done in different boundary conditions (climates and the corresponding building type) using the TRNSYS model. The calculated energy consumptions were used to evaluate the ANN predictions (Fig. 7). The estimation results are represented in (Fig. 8).

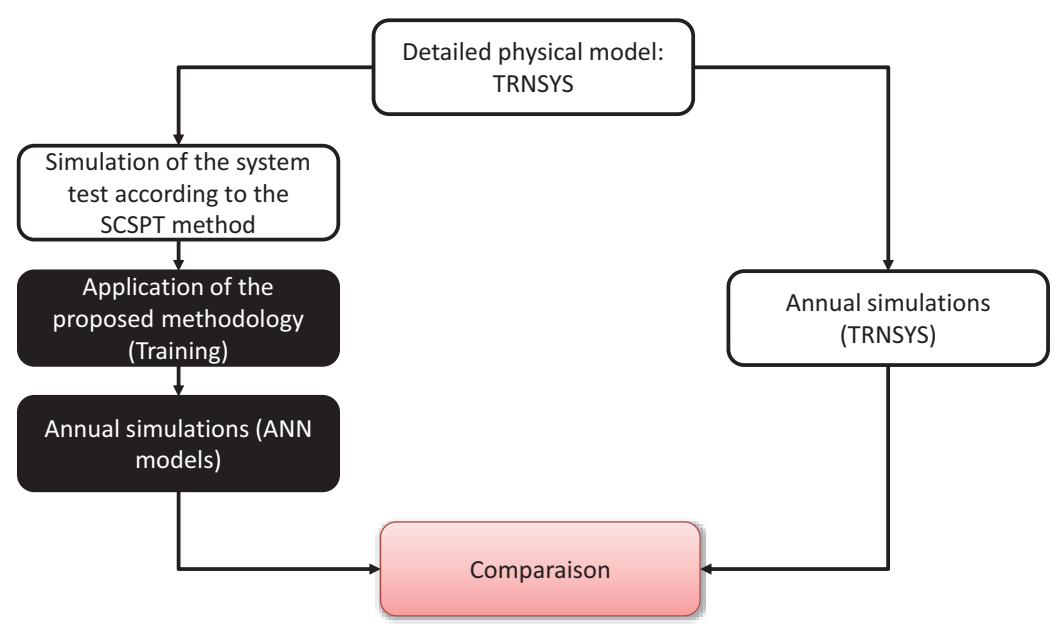

Fig. 7: Validation protocol based on the detailed TRNSYS model 
Tab. 3: Characteristics of the selected ANN models

\begin{tabular}{|c|c|c|c|c|c|c|}
\hline Model & $\begin{array}{c}\text { Normalization } \\
\text { interval }\end{array}$ & $\begin{array}{c}\text { Number of } \\
\text { neurons }\end{array}$ & Output TD & Input TD & AF & $\begin{array}{c}\text { BIC } \\
\text { value }\end{array}$ \\
\hline ANN1 & $\pm 1,0$ & 8 & 3 & 2 & tanh & -0.9946 \\
\hline ANN2 & $\pm 1,0$ & 12 & 2 & 1 & linear & -2.2815 \\
\hline
\end{tabular}

Each bar in the graphs represents the annual energy consumption per square meter of each system, estimated or calculated by the corresponding model in one specific environment (boundary conditions): two with ANN and one using the reference model.

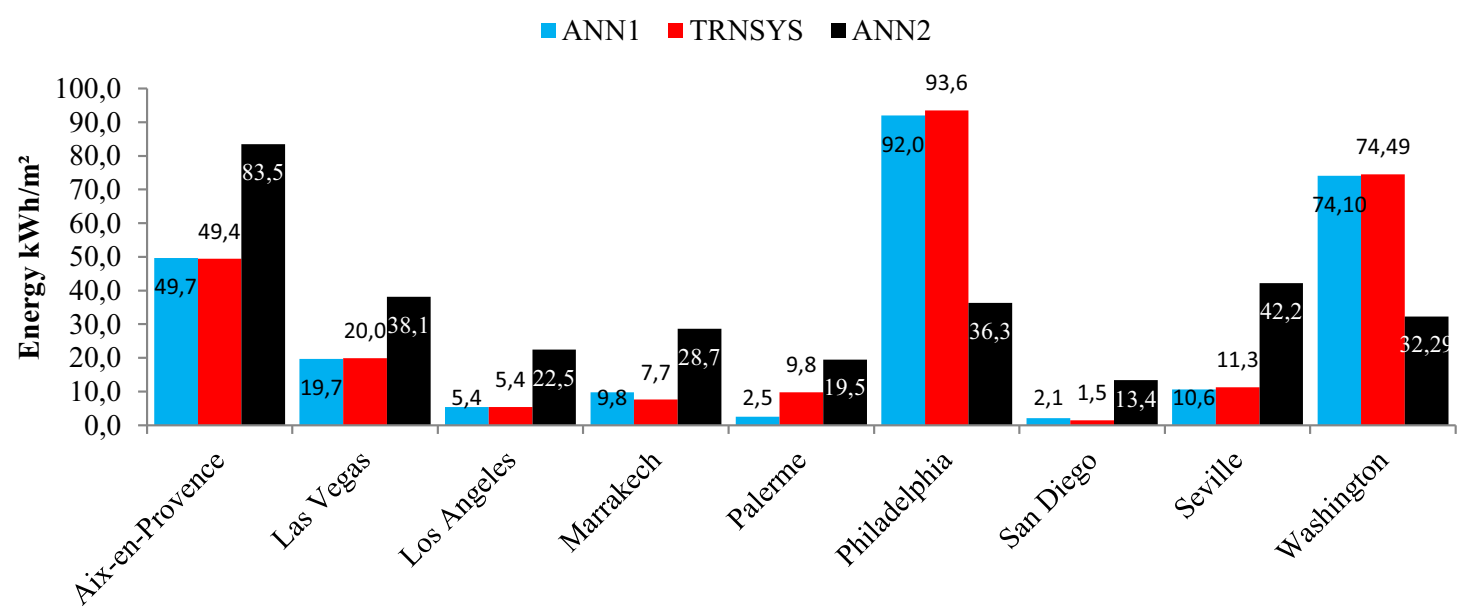

Fig. 8: Comparison of the ANN predictions and the TRNSYS calculations for annual energy consumption

Predictions of the best model ANN1 (Tab. 3) among all those created during the process of the methodology are very accurate. The errors are very low (below 5\%) except for certain climates with low heat demand: Marrakech, Palermo and San Diego. However, the absolute differences are small (maximum of $7.3 \mathrm{kWh} /$ $\mathrm{m}^{2}$, reached in Palermo). The ANN difficulties for these conditions are due to the large differences between the learning conditions and these three climates.

ANN2 model predictions results, selected based on the BIC, reveal the mediocrity of some neural models as the statistical criterion may select. However, this model is easily detectable from the ones that must be discarded. In fact, according to the ANN2 model the annual consumption of the system in Aix-En-Provence is comparable or even greater than its consumption in Philadelphia or Washington. But this is impossible. Another ANN model that respects the trends of energy consumption depending on the climate, only among the selected models according to each configuration (normalization interval, delays and FA), was selected (Tab. 4). The results of the corresponding estimates are shown in (Fig. 9). Estimates of consumption of the system by the new neural model have greatly improved for all climates.

Tab. 4: Characteristics of the selected ANN model ( $2^{\text {nd }}$ selection)

\begin{tabular}{|c|c|c|c|c|c|c|}
\hline Model & $\begin{array}{c}\text { Normalization } \\
\text { interval }\end{array}$ & $\begin{array}{c}\text { Number of } \\
\text { neurons }\end{array}$ & Output TD & Input TD & AF & $\begin{array}{c}\text { BIC } \\
\text { value }\end{array}$ \\
\hline ANN2 & $\pm 0,2$ & 7 & 3 & 2 & $\tanh$ & -1.0226 \\
\hline
\end{tabular}




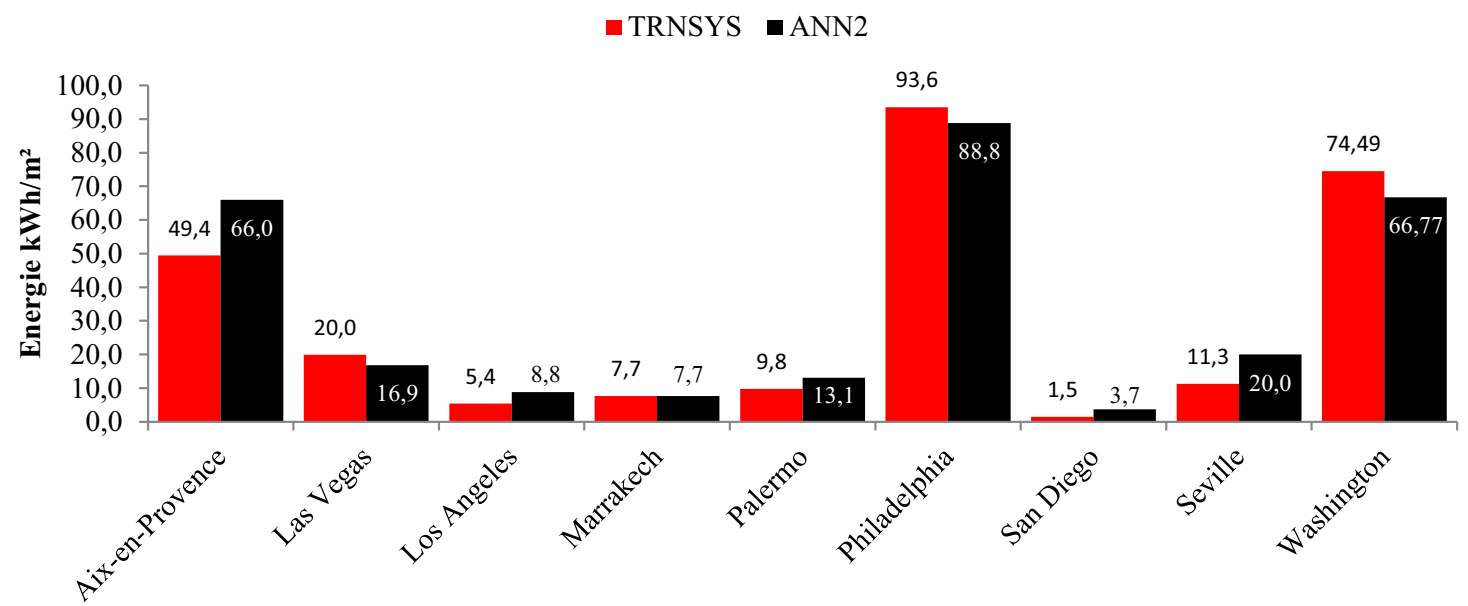

Fig. 9: Comparison of the ANN predictions and the TRNSYS calculations for annual energy consumption. Case of the ANN that has the characteristics presented in (Tab. 4)

In (Fig. 10) is given an example of the power consumption of the system in function of time during the cooling season (case of Philadelphia and ANN2). The goal of the method is to estimate the overall energy consumption and not to reproduce the exact dynamic of the system (however this is needed in the case of a control system). On the whole the model correctly follows the true evolution of the power; this shows that the differences observed in the case of certain climates occur during the heating season (winter). Creating a model per period (heating and cooling) would have probably given better results. This conclusion will be taken into account for future work.

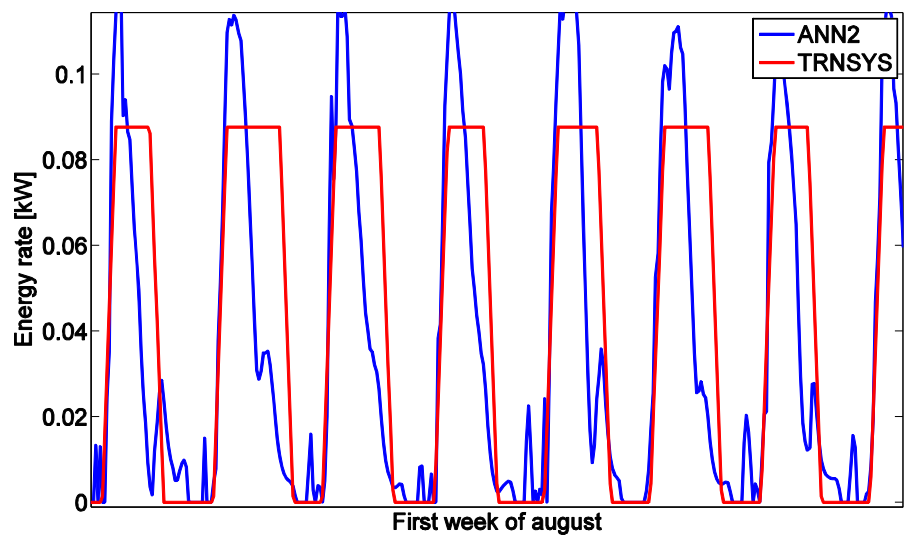

Fig. 10: ANN and TRNSYS outputs, case of the Philadelphia climate

\section{Conclusion}

The presented results show that the methodology developed extension to new systems such as SCS combined with absorption chillers is possible. In fact the best ANN model was able to predict with a satisfactory degree of precision, the annual energy consumption of the evaluated system, in different conditions, based on a learning sequence lasting only 12 days. In fact, the annual energy prediction errors were less than 5\% in most cases. The methodology limitations appear in extreme boundary conditions compared to those used during the ANN training process. Results show also that the statistical criterion BIC is not able to select the best ANN model.

\section{Acknowledgment}

This work has been supported and funded by the French Agency for Environment and Energy Management (ADEME) and the National Institute of Nuclear Sciences and Techniques (INSTN). 
The authors would like to greatly thank the Air Eau Environnement association which financially supported the participation to this congress.

\section{References}

Cybenko, G. (1989). Approximation by Superpositions of a Sigmoidal Function. Math. Control Signals Systems, 2, 303-314.

Dreyfus, G. (2005). Neural networks methodology and applications. Springer.

Eur'Observ'ER. (2013, Mai). Solar Thermal and Concentrated Solar Power Barometer. Systèmes Solaires.

Haller, M., Haberl, R., Persson, T., Bales, C., Kovacs, P., Chèze, D., et al. (2013). Dynamic whole system testing of combined renewable heating systems - The current state of the art. Energy and Buildings, 66, 667677.

Haller, M. (2012). Dynamic Collector Model by Bengt Perers" Updated Input-Output Reference. Institut für Solartechnik, Rapperswil (Switzerland).

Kalogirou, S. (2001). Artificial neural networks in renewable in renewable energy systems application: a review. Renewable and Sustainable Energy Reviews, 5, 373-401.

Khosravi, A., Nahavandi, Creighton, D., \& Saeid. (2013). Quantifying uncertainties of neural network-based electricity price forecasts. Applied Energy, 112, 120-129.

Lazrak, A., Boudehenn, F., Bonnot, S., Leconte, A., Fraisse, G., Papillon, P., et al. (2015). Development of a dynamic artificial neural network model of an absorption chiller and its experimental validation. Renewable Energy.

Lazrak, A., Leconte, A., Chèze, D., Fraisse, G., Papillon, P., \& Souyri, B. (2015). Numerical and experimental results of a novel and generic methodology for energy performance evaluation of thermal systems using renewable energies. Applied Energy, 158, 142-156.

Lazrak, A., Leconte, A., Fraisse, G., Papillon, p., \& Souyri, B. (2014, mai 21-22). Vers une méthodologie générique de modélisation par réseaux de neurons des systèmes énergétiques dans le bâtiment. IBPSA, 8 . Arras, France.

Leconte, A., Achard, G., \& Papillon, P. (2012). Global approach test improvement using a neural network model identification to characterise solar combisystem performances. Solar Energy, 86, 2001-2016.

MacKay, D. (1992). Bayesian interpolation. Neural Computation, 4(3), 415-447.

Norgaard, M., Ravn, O., Poulsen, N., \& Hansen, L. (2000). Neural networks for modelling and control of dynamic systems. Springer.

Qia, M., \& Zhangb, G. P. (2001). An investigation of model selection criteria for neural network time series forecasting. European Journal of Operational Research, 132(3), 666-680.

Ziegler, F., Hellmann, H.-M., \& Schweigler, C. (1999). An approximative method for modeling the operating characteristics of advanced absorption chillers. 20th Int. congress Refrigeration. Sydney. 